\title{
LA SUPRESIÓN DE LAS NOTICIAS IMPORTANTES*
}

\section{Edward Alsworth Ross}

La mayoría de las críticas que se lanzan contra los diarios apuntan a un objetivo equivocado. Por supuesto que los diarios sensacionalizan el vicio y el delito, exageran trivialidades, explotan los asuntos privados de gentes prominentes, embarullan los hechos, y ofenden al buen gusto con griterío, estruendo y colorido. Todas estas cosas pueden ser tan sólo los medios de satisfacer la demanda, de "darle al público lo que desea». No cabe esperar que el periódico se mantenga digno y serio ahora que abastece a millones de gentes comunes, en lugar de hacerlo, como antes, a las clases profesionales y empresariales. Para interesar al chico de los recados, a la obrera de una fábrica y al rudo inmigrante, el periódico tiene que ser picante, divertido, emotivo y cromático. Entonces, por esto, hay que culpar al pueblo estadounidense.

* Edward Alsworth Ross publicó el artículo «The suppression of important news» en la revista Atlantic Monthly, el año 1910. Posteriormente lo recogió en Changing America: studies in contemporary society, Nueva York: Century, 1912, pp. 109-136. El texto fue más tarde incluido en el libro editado por William Grosvenor Bleyer, Profesor de Periodismo en la Universidad de Wisconsin, The profession of journalism (a collection of articles on newspaper editing and publishing, taken from the Atlantic Monthly), Boston: The Atlantic Monthly Press, 1918, pp. 79-96. La traducción correponde al texto de la edición de Bleyer.

\section{Reis}


Pero hay precisamente un cargo tremendo, irrecusable, contra el diario tal como está evolucionando, y es que, concretamente, no da las noticias.

A pesar de todas sus pretensiones, muchos diarios no están «dando al público lo que éste quiere». A pesar de todos esos prodigios tan proclamados de una «empresa» periodística costosa, de los reporteros investigadores y corresponsales apresurados, las líneas alquiladas y los trenes especiales, las noticias, las buenas noticias «vivas», "material al rojo vivo», están siendo deliberadamente suprimidas o distorsionadas. Esto sucede ahora con más frecuencia que antes, y todo lleva a pensar que proseguirá con mayor frecuencia todavía en el futuro.

$\mathrm{Y}$ eso a pesar del hecho de que las aspiraciones de la prensa han sido ascendentes. La venalidad ha disminuido. Cada vez hay mejores hombres atraídos por el periodismo, y éstos han trabajado con más autocontrol. La época en que podía decirse, como se dijo del Reverendo Dr. Dodd, que alguien había «descendido tan bajo hasta convertirse en director de un periódico" parece tan remota como la época de las glaciaciones. El director/periodista que utiliza su periódico para difundir sus prejuicios, satisfacer sus resentimientos y servir a sus ambiciones privadas está desapareciendo. Moderado por una creciente advertencia de su función social, el periodista ha alcanzado un sentido de la responsabilidad. No hace mucho parecía como si un espíritu y una ética profesionales fueran a inspirar el mundo del periódico; y con tal fin se crearon cursos y escuelas de periodismo, con grandes esperanzas. La detención de este movimiento prometedor explica por qué nueve de cada diez periodistas que tengan una experiencia superior a quince años son unos cínicos.

Como es habitual, no hay que condenar a nadie. La apostasía de la prensa diaria se debe a tres desarrollos económicos en el campo del sector editorial.

En primer lugar, el diario de la gran ciudad se ha convertido en un asabanado con un trabajo elaborado de prensa, impreso en ediciones gigantescas que hay que producir en el menor tiempo posible. Los talleres son tan costosos, y la cuota de la Associated Press tan cara, que el diario de una gan ciudad se ha convertido en una empresa capitalista. Actualmente, un millón de dólares no bastaría para comenzar la edición de un diario metropolitano. El director ya no es el dueño, porque no tiene $-\mathrm{y}$ no puede controlarlo- el capital necesario para crear el diario o para comprarlo. El director al estilo de Greeley, Dana, Medill, Story, Halstead y Raymond, que es dueño del diario y lo convierte en su «cuerpo espiritual», la proyección de su carácter y de sus ideas, es extraño. Quizás el señor Watterson y el señor Nelson [el difunto R. Nelson, del Kansas City Star] son los mejores representantes recientes de este tipo de director.

Cada vez más, el propietario de un gran diario es un hombre de negocios que no acaba de ver por qué debería gestionar su negocio de modo distinto a como lo hace el propietario de un hotel, el empresario de espectáculos o el pro- 
pietario de un parque de atracciones. Los directores son personas contratadas, y no pueden publicar en el periódico más que aquella parte de su conciencia y de sus ideales que sea compatible con obtener los mejores resultados económicos de la inversión. Por supuesto, el director de los tiempos pasados que era dueño del periódico quería ganar dinero — ¡no hay pecado en ello!- - pero lo intentaba, concretamente, del mismo modo que el autor de hoy, el conferenciante, o el académico tratan de ganar dinero, dentro de las limitacione impuestas por sus principios y sus estándares profesionales. Pero, ahora que el que proporciona el capital del periódico contrata al director en lugar de ser el director el que contrata el capital del diario, es más probable que el diario sea dirigido como un puro y simple medio de hacer dinero: una fábrica en la que la tinta y las mentes se aplican sobre un papel en blanco para conseguir el producto más vendible que sea posible. No quiere decirse que el dueño del capital haga daño; pero no le preocupan los estándares que estorban al director propietario. Aquél sigue unas pocas máximas sencillas, que funcionan bien para vender zapatos, o cigarros o partituras musicales: «dar a la gente lo que la gente quiere, no lo que usted quiere». "No apoye nada que pueda ser impopular». "Saque todo lo que pueda del negocio».

A este desplazamiento del control a las manos de personas con motivaciones comerciales es a lo que llamamos «la comercialización de la prensa».

La importancia de esto es manifiesta cuando se considera el segundo desarrollo económico; en concreto, el crecimiento de la publicidad ${ }^{1}$ en la prensa. La difusión de noticias y la de publicidad e información interesada son dos funciones esencialmente diferentes que, por razones de conveniencia, son realizadas por la misma organización. La primera tarea se refiere a los suscriptores; la segunda, a los anunciantes. La primera exige buena fe; la segunda, no. La primera es la piedra angular de la libertad y de la democracia; la segunda es una conveniencia comercial. Ahora bien, proporcionar publicidad se está convirtiendo en la principal preocupación del periódico, y amenaza con ensombrecer la comunicación de noticias y de opiniones. Cada año que pasa, la venta de publicidad proporciona una cantidad cada vez mayor de los ingresos totales, y los suscriptores una cantidad más pequeña. Hace treinta años, la publicidad proporcionaba menos de la mitad de los ingresos de los diarios. Hoy proporciona dos tercios. En los periódicos grandes los ingresos publicitarios son varias veces los de los lectores, y en algunos casos constituyen el noventa por ciento de los ingresos totales. A medida que el diario se extiende a ocho, doce, dieciséis páginas, mientras que el precio baja de tres, a dos, a un centavo, se acerca el momento en que los anunciantes paguen el periódico. Los lectores están para

Ross usa de modo indistinto las palabras publicity y advertising, que deberían entenderse como información interesada y publicidad en sentido estricto. En la época en que escribe Ross, Ivy Lee ha comenzado a desarrollar la publicity, que consiste, según explicaba, en ofrecer información, que los periódicos publicarían o no con libertad. En esa época la publicity, precedente de las relaciones públicas en sentido más estricto, comenzaban a practicarla las empresas de diverso tipo, y especialmente las ferroviarias, a las que el autor se refiere más adelante. 
leer, no para aportar los fondos. $\mathrm{Y}$ «el que paga manda»: cuando las columnas de noticias y la página editorial son un mero incidente en la venta rentable de la publicidad mercantil, resulta estrictamente "práctico" el permitir que los anunciantes censuren aquéllas.

Desde luego, no se debe revelar el secreto, o se perderían lectores, y con ello publicidad. Como lo expuso francamente el experto en publicidad Deweese, «el lector debe ser embaucado con la idea de que el editor está publicando realmente el periódico para él». El propietario sagaz «mantendrá el engaño hermoso e impresionante de que dirige un periódico para influir en la opinión pública, para depurar la política, para elevar la moral pública, etc.» En último análisis, entonces el silenciamiento de los hechos en deferencia al anunciante encuentra un límite en la inteligencia y vigilancia del público lector. Manejado como una "propuesta comercial», el periódico no se atreve a suprimir las noticias más allá de un cierto punto, y siempre puede señalar orgullosamente las noticias no suprimidas como prueba de su independencia y de su espíritu a favor del público.

La inmunidad de que disfruta el gran anunciante se hace más seria a medida que son más los negocios que recurren a la publicidad. Antes, los lectores que entendían por qué nunca ocurrían accidentes ni se producían problemas laborales en los grandes almacenes, por qué las críticas de espectáculos eran tan complacientes, y las reseñas de libros de los editores que se anunciaban tan bondadosas, todavía podían esperar de su diario una libertad no amordazada cuando tratara del gas, de la electricidad, del ferrocarril y de los bancos. Pero ahora las empresas de gas hacen publicidad: "Cocine con gas»; las eléctricas le animan a uno a enchufar la máquina de coser a su corriente, y las empresas ferroviarias despilfarran océanos de tinta para atraer colonos o turistas. Los bancos y las compañías de inversiones compran espacio, la inversión publicitaria ha brotado como el árbol de Jonás, y las empresas telefónicas y de transporte se han lanzado al torbellino de la competencia en publicidad. Actualmente, en las columnas de noticias del periódico que se orienta por la caja registradora, todas las empresas que buscan favores, o reglamentos que evadir, serán capaces de pisar el silenciador.

Un tercer desarrollo es la subordinación de los periódicos a otras empresas. Una vez que un periódico se convierte en un producto que ha de ser rentable, separable de la personalidad del director, que puede ser comprado y vendido como un hotel o un molino, puede llegar a manos de gentes que lo mantendrán sometido a otras inversiones más importantes. El magnate propietario puede encontrar ventajoso no dirigirlo como un periódico puro y simple, sino convertirlo - de modo subrepticio - en un instrumento para dar color a ciertos tipos de noticias, difundir cierta desinformación, o difundir ciertas impresiones o prejuicios entre su clientela. En una palabra, puede modelar su política editorial de acuerdo con consideraciones no periodísticas. Al hacer que su periódico ayude en sus otros planes, o que promueva sus ambiciones políticas o sociales, lo perjudicará como un medio de ganar dinero, sin duda, pero puede ingeniár- 
selas para engañar a suficiente gente el tiempo suficiente. Aparte de tal esclavitud, los periódicos están sometidos a la tendencia de diversos hombres de negocios a vincularlos con las inversiones cruzadas del propietario. Pero, naturalmente, cuando las acciones de un periódico están en el depósito de seguridad junto a las acciones del gas, del teléfono y del oleoducto, es probable que la "ternura" por esos intereses colaterales afecte a las columnas de noticias.

\section{III}

Que, como consecuencia de su comercialización y de su frecuente sumisión a intereses externos, el periódico diario está suprimiendo constantemente noticias importantes, se verá con los ejemplos que siguen. Constituyen apenas un tercio del material que ha llamado la atención al autor.

Un prominente fabricante de tejidos de Filadelfia en visita a Nueva York fue descubierto pervirtiendo a niños y se degolló. Como su empresa era un gran anunciante, ni siquiera un diario de su ciudad mencionó la tragedia. Un periódico de Nueva York se aprovechó de la situación y envió una edición extra con la información. La empresa en cuestión tiene una sucursal importante en una ciudad del Oeste; allí también la prensa local se mantuvo en silencio, y la oportunidad la aprovechó un periódico de Chicago.

En la misma ciudad del Oeste el vicepresidente de esta empresa fue procesado por sobornar a un concejal para que aprobaran una ordenanza que autorizara la construcción de un puente sobre una avenida, para unir dos de los edificios de la empresa. Representantes de la empresa pidieron a los periódicos en que hacían publicidad que ignorasen el juicio. En consecuencia, los cinco diarios en inglés no publicaron nada acerca de éste, que duró una semana y reveló asuntos verdaderamente sensacionales. Sólo los periódicos en alemán enviaron reporteros al juicio y publicaron los debates.

En un gran centro industrial, uno de los casos más prominentes del fiscal de distrito de los Estados Unidos fue el procesamiento de ciertas empresas por falsificar marcas. Los hechos que se descubrieron aparecieron en la prensa de los centros pequeños, pero ni una palabra se publicó en los diarios locales. En otro centro se multó a cuatro empresas por vender queso enlatado que había sido tratado con conservantes; los diarios locales publicaron los hechos, pero ocultaron los nombres de las empresas: una consideración que no es probable que se tenga con un acusado común.

En un juicio en una gran ciudad se supo por testimonio con juramento que, durante un problema laboral reciente, que implicó a transportistas por un lado y a los almacenes y empresas de ventas por correo por otro, los empleadores habían conspirado para provocar a los huelguistas a la violencia desviando fuera de su camino una caravana de vehículos que no respetaban la huelga, para que pasaran por un lugar en el que estaban reunidos los huelguistas. Estos vehículos eran el cebo de una trampa, pues un contingente de policias se había reu- 
nido en los alrededores, dispuesto para el caso, y el gobernador del Estado estaba al lado del teléfono, dispuesto a llamar a la milicia en el caso de que surgiera una revuelta. Afortunadamente, los huelguistas se contuvieron y no funcionó la trampa. Es fácil imaginar cuáles habrían sido los titulares en el caso de que los trabajadores se hubieran implicado en un plan tan diabólico. Con todo, los diarios, unánimemente, se negaron a publicar este testimonio.

En la misma ciudad, durante una huelga de los ascensoristas en los grandes almacenes, el representante de su sindicato fue golpeado hasta la muerte, en una avenida detrás de cierto almacén, por un matón pagado para ese fin. La historia, apoyada con tres testimonios notariales, la entregó un abogado responsable a tres periodistas, que la aceptaron como verdadera y prometieron publicarla. El relato no apareció nunca.

En otra ciudad las dependientas de las grandes tiendas tuvieron que firmar un contrato mezquino y abusivo que, si se hubiera conocido, habría hecho que las empresas resultaran odiosas ante el público. Una asistente social destacada entregó esos contratos, con pruebas de las malas condiciones que se habían establecido de acuerdo con ellos, a los diarios de la ciudad. Ninguno imprimió una línea del asunto.

Al producirse una huelga justificable de los tranviarios, los periódicos estaban dispuestos a tratarla de un modo favorable. De pronto cambiaron y se convirtieron unánimemente en hostiles a los huelguistas. La investigación demostró que los grandes comerciantes habían amenazado con retirar sus anuncios, a menos que los periódicos cambiaran su actitud.

En el verano de 1908 se produjeron serios incendios en la zona de los lagos del Norte, y se destruyeron grandes depósitos de maderas almacenadas. Un órgano prominente de la industria maderera redujo las pérdidas e imprimió declaraciones tranquilizadoras de madereros que en ese mismo momento estaban llamando al Estado pidiendo una patrulla de bomberos. Cuando se le acusó del engaño, el órgano alegó su obligación de apoyar al mercado, porque las empresas madereras de la región de los lagos habían hecho publicidad de bonos en sus columnas.

Acusándolo de agitación a favor de las pensiones de los maestros, un maestro fue expulsado sumariamente por un consejo escolar corrupto, violando sus propias normas publicadas referentes a los puestos en propiedad. Un diario influyente publicó los hechos referentes al soborno del consejo escolar durante el juicio que incoó el maestro para que lo repusieran en su puesto; hasta que un comerciante importante, a través de sus conocidos de un club al que pertenecía, fue inducido a amenazar al diario con la retirada de su publicidad. Dejaron de aparecer más informaciones sobre aquellas revelaciones.

Durante las disputas laborales los hechos son distorsionados habitualmente en perjuicio de los trabajadores. En cierta ocasión los huelguistas celebraron una reunión en un espacio cerrado por vallas para carteles recién instaladas. Enseguida apareció en la portada de un diario sensacionalista, que manifestaba una "cálida amistad» hacia los trabajadores, un grabado de la valla y una fantás- 
tica historia de cómo los huelguistas habían construido una «estacada» tras la cual pretendían desafiar a los policías. No puede sorprender que, cuando el vehículo que distribuía esas hojas mentirosas pasó por ese barrio de la ciudad, los difamados lo volcaran.

Durante la lucha de los conductores de coches de caballos por una semana de seis días, algunos grandes diarios se prestaron a un esfuerzo concertado con los responsables de los establos de alquiler de caballos, para ganarse la simpatía del público haciendo que los huelguistas aparecieran como si estuvieran interfiriendo los funerales. Un diario dijo falsamente que un fuerte contingente de policías estaba dispuesto, en reserva, por si se producían «revueltas» y que los policías cabalgarían junto a los conductores no sindicados de los coches fúnebres. Otro, bajo el titular engañoso «Dos funerales impedidos por los conductores», describía inocentes coloquios entre los conductores de los coches fúnebres y los piquetes. A esto seguía un solemne editorial: "iPuede un ser humano irse en paz a su último descanso?»; aunque, de hecho, los huelguistas no tuvieron intención de estorbar los funerales.

El titular mentiroso es un instrumento favorito para engañar al lector. Un diario publica en su portada un enorme titular «aterrorizante»: "Ahorquen a Haywood y un millón de personas marcharán para vengarlo", dice Darrow». Los pocos lectores cuya mirada pasó del titular incendiario al texto de la información sólo encontraron lo que sigue: «El señor Darrow, al acabar su intervención, dijo que "si el jurado cuelga a Bill Haywood, un millón de manos voluntarias tomarán la bandera de la libertad junto a la tumba abierta, y la portarán hasta la victoria" "Con el mismo estilo, un despacho acerca de la muerte de un policía inglés, a causa de las heridas recibidas durante una revuelta producida por las sufragistas que intentaban entrar en un local durante un mitin político, lo titulan: «¡Las sufragistas matan a un policía!».

La animosidad con la que muchos diarios sirven como portavoces de los poderes financieros se hizo ver con mucha claridad durante la reciente depresión industrial. El propietario de un diario importante reunió a sus reporteros y les dijo: "Muchachos, el primero de ustedes que venga con una historia sobre un despido o un cierre queda despedido». Al comienzo de la depresión los diarios estaban llenos de noticias sobre la reaperturea de las acererías y la revitalización de los negocios, todo ello sin fundamento. Después de la cosecha comenzaron a gorjear: "Prosperidad», "Mejor que nunca», "Los agricultores compran automóviles». En las ciudades en las que los bancos y los empresarios ofrecían vales de compra en lugar de dinero en efectivo, la prensa imprimió habitualmente cuentos de hadas sobre el entusiasmo con el que estas medidas fueron acogidas por los ahorradores y trabajadores. El número y los sufrimientos de los desempleados fueron implacablemente escondidos al público lector. Un gran mitin de hombres sin trabajo fue presentado como "anarquista» o "instigado por los socialistas con fines políticos». En un diario apareció una noticia bajo el titular «Se ofrecen cinco mil puestos de trabajo; sólo diez los solicitan». Decía que el comisario de obras públicas de Detroit, mal orientado por informaciones 
sobre la horrible miseria, había puesto en marcha una obra pública que requería cinco mil trabajadores; y que sólo diez personas solicitaron el trabajo y todos ellos esperaban ser jefes. La correspondencia con el comisario estableció el hecho de que ¡el número de puestos ofrecido era de quinientos y que tres mil personas habían solicitado trabajo!

\section{IV}

Sobre las mesas del director y de los redactores-jefes de un periódico gestionado por un capitalista promotor, que cumple ahora (1910) sentencia de prisión, había una lista de dieciséis empresas en las que el propietario del periódico estaba interesado. La finalidad era recordarles que no se publicara nada que pudiera dañar a esas empresas. En la redacción se llamaba jocosamente a estas empresas las «vacas sagradas».

En la manada de las «vacas sagradas» veneradas por la prensa diaria se puede encontrar todo tipo de privilegios.

La empresa ferroviaria es una «vaca sagrada». En una sesión pública ante una comisión ferroviaria estatal, el abogado de una asociación de transporte marítimo logró convocar a la silla de los testigos a un magnate importante, con la intención de extraerle la verdad con respecto a los gastos políticos de su ferrocarril. En ese momento la comisión, una abyecta criatura de las empresas ferroviarias, excluyó arbitrariamente del caso al atrevido abogado. Se hizo que la dura crítica que el abogado expresó a la cara de los componentes de la comisión apareciera en los periódicos como la causa, y no como la consecuencia de su exclusión. Posteriormente, cuando el abogado presentó una denuncia ante el gobernador contra la comisión, un periodista escribió un artículo editorial dando a conocer los hechos y criticando a los miembros de la comisión. El editorial fue suprimido cuando ya estaba listo en galeradas.

La empresa de servicios públicos es una "vaca sagrada». En una ciudad del Sudoeste, el verano pasado (1909), cuando varias casas estaban ardiendo por falta de agua para las mangueras de los bomberos, una empresa maderera se ofreció a suministrarles agua. El servicio de aguas replicó que ya tenían «suficiente». Ni esta ni ninguna otra información perjudicial referente al comportamiento del servicio de aguas consiguió entrar en las columnas de la prensa local. Un periódico sensacionalista destacado por su lucha por un gas más barato y sus feroces ataques a la compañía de gas cesó repentinamente en sus ataques; enseguida comenzó a ofrecer un anunció a toda página que decía "Cocine con gas»: la vaca había encontrado la entrada al redil sagrado.

Los transportes son otra «vaca sagrada». La verdad sobre la lucha en Cleveland por una tarifa de tres centavos ha sido ampliamente silenciada. Por ejemplo, cuando el alcalde Johnson estaba supervisando la retirada de los raíles de un tranvía ya inexistente, se le entregó un interdicto del juez para impedirlo. Como el interdicto no estaba confirmado, tal como requería la ley, pensó que 
era una comunicación ordinaria, y se lo echó al bolsillo para leerlo más tarde. Al día siguiente fue convocado para que diera razones para que no lo acusaran de desacato. Desde luego, cuando se conocieron los hechos, se retiraron los cargos. Un examen de los siete diarios más importantes del país muestra que se envió un despacho desde Cleveland diciendo que el alcalde Johnson, después de agradecer el servicio, se guardó el interdicto en el bolsillo y mandó a sus hombres que siguieran con su trabajo. En las oficinas de los periódicos embrollaron el asunto. Uno dijo que el alcalde había dicho a sus hombres que siguieran adelante ignorando la orden. Otro señaló que el alcalde había dado a entender de antemano que no obedecería una orden, si ésta llegara. Un tercer periódico inventó una conversación en la que el alcalde y el supervisor de la obra se burlaban del interdicto. Ninguno de los siete diarios informó de la posterior exoneración total del alcalde.

El sistema fiscal es otra "vaca sagrada». Durante un banquete de doscientos contribuyentes, al final de un congreso estatal, una persona se sintió mal. Los reporteros vieron ese incidente banal, pero los diarios de la mañana, bajo grandes titulares («Muchos intoxicados en el banquete de los contribuyentes»), contaron en detalle que un gran número de comensales habían tenido una intoxicación por alimentos. El congreso había aprobado una enmienda a la Constitución del Estado propuesta por los contribuyentes, que pensaban presentarla a la gente para obtener firmas de acuerdo con la ley de iniciativa; un diario dedicó línea y media a esta acción verdaderamente significativa; ningún otro periódico dio noticia de ello.

El sistema de partidos es otra «vaca sagrada». Cuando un tribunal de distrito de un condado declaró que la enmienda de iniciativa y referéndum a la Constitución de Oregón era inválida, el asunto fue difundido ampliamente. Pero cuando, más tarde, la Corte Suprema de Oregón anuló esta decisión, el hecho resultó demasiado trivial como para incluirlo en las noticias de agencia.

El que «está arriba» es una «vaca sagrada». Al informar sobre los argumentos del fiscal Heney en el caso Calhoun, el periódico más importante de San Francisco omitió todo lo referente a la culpabilidad de Calhoun, y dio pábulo a ciertas afirmaciones del señor Heney con referencia a sí mismo, con el intento de que su argumento pareciera más una autojustificación, y que no había dicho nada contra el acusado. El argumento de la defensa se imprimió completo, con los puntos principales presentados claramente con tipos más grandes y espacios adecuados. En un momento de crisis en este proceso, un despacho de Washington citaba al presidente del Comité de apropiaciones diciendo en el Congreso que «el señor Heney recibió, durante 1908, 23.000 dólares, por los que no hizo servicio alguno para el gobierno». Fue horas antes de que el informe se corrigiera añadiendo las palabras finales del señor Tawney: «durante aquel año».

En vista de la supresión y representación deficiente de la verdad vital que hacen los grandes diarios, hablando en términos generales, deben considerarse como aliados de aquellos a los que - como dijo reverentemente el director Dana- «Dios ha otorgado un don para ahorrar, para enriquecerse, para reunir 
riquezas, para acumular y concentrar dinero». Para ponerse al lado del pueblo son más lentos que los semanarios, las revistas, el púlpito, la tribuna, los abogados, la gente instruida, los intelectuales y las universidades.

Desde luego, ahora y entonces, en alguna ciudad traicionada y mal gobernada, un hombre con arrestos se hace con algún pequeño periódico, imprime todas las noticias, da cuenta de la situación local, impulsa a la comunidad, logra una enorme tirada, y demuestra que decir la verdad todavía compensa. Pero tales hazañas no contrarrestan los desarrollos económicos que nos han traído hasta la época glacial del periodismo. Adviértase lo que sucede posteriormente a tal periódico: se convierte en una propiedad valiosa, y será tratada como tal. El director no necesitará repetir los golpes audaces con los que consiguió la confianza del público; sólo tiene que evitar cualquier cosa que la perjudique.

¿Qué puede hacerse respecto de la supresión de las noticias? Al menos podemos desistir de criticar y predicar. Urgir al director, sometido al anunciante o al propietario, a ser más independiente es invitarle a que abandone la profesión. En cuanto al capitalista propietario, exhortarlo para que maneje su diario en interés de la verdad y del progreso es tan razonable como tratar de convencer al molinero para que maneje su propiedad en favor del bien general en lugar de en su beneficio privado.

Lo que hace falta es abrir un camino nuevo y amplio para la conciencia pública. Algunos hechos silenciados ya se están abriendo brecha por sí mismos. La moda extendida de las revistas escandalosas (los «muck rack» magazines) se debe a que son vehículos de noticias suprimidas. Líderes independientes están encontrándose con una respuesta entusiasta cuando fundan semanarios para llegar a su público natural. El partido socialista mantiene dos diarios, menos para difundir sus ideas que para imprimir lo que silenciarían los periódicos capitalistas. Las asociaciones cívicas, las ligas de votantes municipales, y las de votantes para los parlamentos estatales, están poniendo en circulación toneladas de folletos y boletines repletos de hechos suprimidos. En un año (1909-10) cinco ciudades, con el dinero de los contribuyentes, han comenzado periódicos para familiarizar a los ciudadanos con los sucesos y los asuntos municipales. En muchas ciudades han surgido semanarios privados independientes para ofrecer información cívica. Aún más: la palabra hablada vuelve a ser un poder; la demanda de conferenciantes y oradores es insaciable, y todo hace pensar que la tribuna recuperará su antiguo prestigio. Los silenciadores están descorazonados por el crecimiento del circuito Chautauqua ${ }^{2}$. Las intervenciones en el congreso

2 Se refiere a una institución de finales del XIX y comienzos del XX, en la que se ofrecía educación popular combinada con entretenimiento en forma de conferencias, conciertos y obras teatrales. 
airean la verdad boicoteada, y la hacen circular ampliamente utilizando el privilegio de franqueo. Se han constituido clubes ciudadanos y clubes para comer los sábados, con objeto de escuchar los hechos y las ideas convertidas en tabú por la prensa diaria. Se da más importancia a las sesiones públicas de los comités de consejeros o legisladores.

Sin embargo, aun teniendo en cuenta todo esto, la defección de la prensa diaria ha sido un golpe que ha hecho tambalearse a la democracia.

Muchos insisten en que el público es capaz de reconocer y de pagar por la verdad. "Confía en el público», y al final el mérito tendrá su recompensa. Una y otra vez los hombres han invertido dinero para comenzar un periódico honesto y franco, confiando en que el público acudiría pronto a apoyarlo. Pero estas esperanzas están condenadas a la decepción. El director que rechaza la mala publicidad o que desafía a sus grandes patronos no puede dejar su ejemplar a la puerta del suscriptor por tan poco dinero como el director que busca publicidad a toda costa; y las masas no pagarán tres centavos cuando otro periódico que «parece igual de bueno" puede conseguirse por un centavo. En una palabra, el arte de simular la honestidad y la indepedencia ha superado la agudeza del lector medio.

Concluir que la gente no es capaz de reconocer y de pagar por la verdad acerca de los sucesos actuales sitúa simplemente la difusión de noticias en la misma clase que otros servicios sociales de máxima importancia. Porque la gente no consigue reconocer y pagar por los buenos libros, se han fundado bibliotecas que cubren el país. Porque la gente no consigue reconocer y pagar por la buena educación, ésta se proporciona gratis o barata. Así como llegó el momento en que se vio que las escuelas, las bibliotecas de préstamo, los parques comerciales, los baños, los gimnasios y zonas deportivas, y las zonas de juegos infantiles privados no serían suficientes, del mismo modo ha llegado el momento de reconocer que el medio de información comercial no satisface adecuadamente las necesidades de la ciudadanía democrática.

Hacen falta fundaciones, y puesto que aún no somos lo suficientemente sagaces para dirigir un diario de propiedad pública, los fondos han de venir de fuentes privadas. Viendo que en quince años se han hecho grandes donaciones, que han supuesto más de mil millones de dólares con fines públicos en este país, no es arriesgado predecir que, si se demostrara la utilidad de un periódico no comercial, los fondos llegarían. En las ciudades, donde el control secreto de los canales de publicidad es más fácil, probablemente se fundarían periódicos financieramente independientes, apoyados por hombres acaudalados con sensibilidad pública.

El control final de una fundación de ese estilo constituye un problema. Un periódico libre que pueda ignorar las amenazas de los grandes anunciantes o de intereses poderosos, un periódico que no se vendiera, dejara intimidar o vapulear, un periódico que pudiera en todo momento revelar la condenada verdad sobre la protección policial al vicio, el fraude fiscal de las empresas, la apropiación de terrenos por los ferrocarriles, o el incumplimiento de las leyes laborales, 
sería de una importancia estratégica tan grande en la lucha por la riqueza que se harían esfuerzos desesperados para anestesiarlo. Si su consejo de gobierno se perpetuara a sí mismo mediante cooptación, eventualmente estaría lleno de hombres «seguros», que se ocuparían de que el periódico se gestionara con un espíritu "conservador»; porque, a largo plazo, aquellos que pueden vigilar las ventajas todo el tiempo superarían a la gente, que sólo puede vigilar parte del tiempo.

Un periódico constituido como una fundación estará anestesiado, a menos que esté comprometido con el pensamiento y la conciencia progresivos de la comunidad. Y esto podría hacerse dejando que las vacantes en el consejo de gobierno fueran ocupadas por turno por el colegio de abogados local, por el colegio de médicos, por la unión de pastores, las facultades universitarias, la federación de maestros, las centrales sindicales, la cámara de comercio, las entidades filantrópicas, las bibliotecas públicas, las asociaciones ciudadanas independientes y las instituciones sociales. De esta manera la fundación se apoyaría en los ejes principales de aquello moral e intelectualmente valioso en la ciudad.

Mientras ofrece con titulares, grabados y tiras cómicas las noticias interesantes - fraudes y accidentes, sociedad y deportes, así como economía y política-, el periódico constituido como una fundación no dramatizaría el delito, o el cotilleo de los asuntos privados; sobre todo no «falsificaría», «sesgaría» o haría sensacionalismo con las noticias. Respetándose lo bastante como para no seguir tácticas de espionaje por el ojo de la cerradura, y siendo lo bastante serio como para no dar noticias banales de la parafernalia de las bodas y del tribunal de divorcios, un periódico así no podría comenzar igualando la tirada de la prensa comercial; pero llegaría a aquellos que alcanzan al público a través de semanarios y mensuales, e informaría a los maestros, predicadores, profesores universitarios y hombres públicos que hablan a la gente cara a cara.

Más aún, sería un periódico corrector, que ofrecería un punto de apoyo saludable para elevar el nivel de la prensa comercial. Los grandes periódicos no se atreverían a que los pillaran silenciando o "cocinando" las noticias. Las revelaciones de un diario independiente creído por todos serían un terror para aquéllos; y, bajo el acicate de un competidor que no se deja intimidar, comprar o agotar, se verían obligados, aunque sólo fuera por su supervivencia, a decir la verdad más a menudo de lo que lo hacen.

El Canal Erie resuelve menos de una vigésima parte del tráfico a través del Estado de Nueva York y, con todo, con su continua oferta de transporte barato, ejerce una presión reguladora sobre las tarifas del ferrocarril, lo cual se advierte solamente cuando el canal se abre en la primavera. Bajo el mismo principio, el periódico constituido como fundación en una ciudad concreta podría imprimir solamente una vigésima parte de la que ofrece la prensa diaria y, con todo, ejercería una influencia grande y saludable sobre los otras diecinueve partes.

(Traducido por Esteban LÓPEZ-EsCOBAR.) 


\section{CRÍTICA DE LIBROS}

